DOI 10.37882/2500-3682.2020.12.04

\title{
ФАКУЛЬТАТИВНЫЕ ЗАНЯТИЯ КАК СРЕДСТВО РАЗВИТИЯ ПОЗНАВАТЕЛЬНОГО ИНТЕРЕСА У ДЕТЕЙ МЛАДШЕГО ШКОЛЬНОГО ВОЗРАСТА
}

\section{OPTIONAL ACTIVITIES AS A MEANS OF DEVELOPING COGNITIVE INTEREST IN CHILDREN OF YOUNG SCHOOL AGE \\ E. Bogomolova \\ L. Mamedova}

Summary: The modern education system is increasingly faced with the problem of insufficient development of cognitive interest in children of primary school age, which is one of the most important properties of a child's personality, which is necessary both for the harmonious and comprehensive development of his personality and for teaching at school. To solve this problem, we conducted a study on the basis of the Municipal Educational Institution "Gymnasium No. 1 of Neryungri named after S.S. Karimova «. This study was aimed at determining the level of development of cognitive interest in children of primary school age, as well as the students' interest in conducting optional classes under the Around the World program. This would allow us to substantiate the importance of extracurricular activities as a method of working with children that allows us to develop cognitive interest most effectively. The study involved students of grade $3 \mathrm{~A}$ in the amount of 22 people. Comprehensive diagnostics, carried out by us, allowed us to determine the level of development of cognitive interest in children, as well as the importance of using optional classes in the development of cognitive interest.

Keywords: optional activities, level of evolution, cognitive interest, the world, primary school children.

\author{
Богомолова Елена Алексеевна \\ Технический институт (филиал) Северо-Восточный \\ федеральный университет \\ имени М.К. Аммосова в Нерюнгри \\ helen_fletcher@mail.ru \\ Мамедова Лариса Викторовна \\ к.п.н., дочент, Технический институт (филиал) \\ Северо-Восточный федеральный университет \\ имени М.К. Аммосова в Нерюнгри \\ larisamamedova@yandex.ru
}

Аннотация: Современная система образования все чаще сталкивается с проблемой недостаточного развития у детей младшего школьного возраста познавательного интереса, который является одним из важнейших свойств личности ребенка, необходимым как для гармоничного и всестороннего развития его личности, так и для обучения в школе. Для решения данной проблемы нами было проведено исследование на базе МОУ «Гимназия №1 г. Нерюнгри им. С.С. Каримовой». Данное исследование было направлено на определение уровня развития познавательного интереса у детей младшего школьного возраста, а также заинтересованности учениками в проведении факультативных занятий по программе «Вокруг света». Это позволило бы нам обосновать значимость факультативных занятий как метода работы с детьми, позволяющего развить познавательный интерес наиболее эффективно. В исследовании приняли участие ученики 3 А класса в количестве 22 человек. Комплексная диагностика, проведенная нами, позволила определить уровень развития у детей познавательного интереса, а также значимость использования факультативных занятий в развитии познавательного интереса.

Ключевые слова: факультативные занятия, уровень развития, познавательный интерес, окружающий мир, дети младшего школьного возраста.

Познавательный интерес играет существенную роль в гармоничном развитии личности ребенка младшего школьного возраста. Он позволяет учащимся испытывать тягу к знаниям, концентрироваться на желании обучаться и изучать что-то новое. Наибольшее значение развитие познавательного интереса имеет на уроках окружающего мира. Благодаря этому качеству ребенок не только укрепляет свое желание учиться, но и развивает другие качества, например наблюдательность и внимание. Также познавательный интерес способствует формированию и развитию у ребенка логического и ситуативного мышления. Однако если времени непосредственно на уроке окружающего мира недостаточно для того, чтобы наиболее интенсивно развивать познавательный интерес у детей, можно прибегнуть к организации внеурочной деятельности, одним из видов которой являются факультативные занятия. 
Согласно Федеральному Закону №273-Ф3 «Об образовании в Российской Федерации», «начальное общее образование направлено на формирование личности обучающегося, развитие его индивидуальных способностей, положительной мотивации и умений в учебной деятельности» [7, с. 15], что подразумевает собой развитие познавательного интереса у детей как необходимого для дальнейшего обучения и получения иного жизненного опыта качества. Согласно Федеральному государственному образовательному стандарту начального общего образования (утв. приказом Министерства образования и науки РФ от 6 октября 2009 г. N 373), «освоение программы курса «Окружающий мир» предполагает освоение доступных способов изучения природы и общества (наблюдение, запись, измерение, опыт, сравнение, классификация и др., с получением информации из семейных архивов, от окружающих людей, в открытом информационном пространстве)» [6, с. 9].

С.Л. Рубинштейн писал о познавательном интересе следующее: «Это особая избирательная тенденция личности на процесс познания, характер которой выражается в какой-либо определенной области» [3, с. 65].

При изучении научной литературы нами было установлено, что проблемой развития познавательного интереса у детей младшего школьного возраста с помощью различных методов и приемов занимались С.Л. Рубинштейн, Л.И. Божович, Я.А. Коменский, Г.И. Щукина, А.В. Усова, Ф.Н. Гоноболин, И.Ф. Харламов и др.

Поскольку познавательный интерес можно отнести к качествам личности ребенка, его не только можно, но и нужно развивать. Наибольший упор на это стоит сделать во время обучения ребенка в начальной школе, поскольку именно в это время любопытство и любознательность ребенка находятся на достаточно высоком уровне, что порождает интерес к познанию окружающего мира и получению новых знаний в целом. Благодаря познавательному интересу, человек имеет возможность изучить максимально возможное количество вещей, на которые обращает свое внимание. Активное развитие данного качества также позволяет параллельно развивать другие свойства личности, например, мышление, внимание, память, наблюдательность и т.п.

Согласно Г.И. Щукиной, познавательный интерес имеет четыре стадии развития: любопытство, любознательность, познавательный интерес, устойчивый познавательный интерес [8, с. 43]. Каждый из этих уровней развития определяет отношение ребенка к самому процессу познания, к новым знаниям в целом и к дальнейшему развитию такого качества, как познавательный интерес.

Любопытство обусловлено неожиданными, необыч- ными внешними факторами и обстоятельствами, которые привлекают ребенка в данный момент времени. Данная стадия развития познавательного интереса может послужить толчком к более глубокому изучению предмета, к которому ребенок проявляет любопытство, но если предмет, действие или процесс, привлекший внимание ребенка, не сможет удержать это самое внимание на достаточное количество времени, интерес к нему быстро угаснет и не получит дальнейшего развития.

Любознательность уже можно считать целым состоянием личности, которое особенно тем, что у ребенка появляется стойкое желание проникнуть глубоко за пределы объекта, действия или явления, заинтересовавшего его. Любознательность позволяет ребенку погружаться в знания о новом с головой, не останавливаться на минутном интересе к объекту, действию или явлению, а продолжать его изучение. Можно сказать, что эта стадия развития познавательного интереса у каждого ребенка проявляется по-разному, поскольку далеко не все дети любознательны. Существуют и такие дети, которых интересуют конкретные, определенные свойства объекта, явления или действия, и они концентрируют весь свой познавательный интерес только на этих конкретных свойствах, что значительно усложняет его дальнейшее развитие.

Непосредственно познавательный интерес характеризуется появлением у ребенка познавательной активности, развитием ценностной мотивации, в которой главное место занимают познавательные мотивы. Они содействуют проникновению личности ребенка в существенные связи между изучаемыми явлениями, действиями или объектами. На данном этапе каждый ребенок использует методы, наиболее подходящие для него. Одни дети развивают свой познавательный интерес посредством игры, поскольку в игровой форме информация воспринимается ими быстрее и лучше усваивается. Другие учащиеся делают упор на проблемный метод, предпочитая сначала выделить для себя некую «проблему» изучаемого ими объекта, действия или явления. Однако такой метод зачастую требует от ребенка обширных теоретических знаний или проведения каких-либо исследований, в чем может потребоваться помощь учителя.

Устойчивый познавательный интерес формируется у ребенка тогда, когда были пройдены все предыдущие «ступени» развития познавательного интереса. Однако не все дети способны развить в себе устойчивый интерес к какому-то конкретному учебному предмету или же другому объекту, действию или явлению, к которому они ранее проявляли любопытство. Это связано с тем, что в процессе развития познавательного интереса к этому предмету, объекту и т.п. ребенок узнает все интересую- 
щие его аспекты, и дальнейшее изучение темы перестает быть целесообразным. Наиболее серьезной проблемой это становится тогда, когда познавательный интерес формируется к определенному учебному предмету - далеко не каждая тема способна обратить на себя внимание ребенка и вызвать у него интерес. Поэтому развитие устойчивого познавательного интереса является в некоторой степени проблемой для учителя, но особенно не воспринимается ребенком.

На основании информации, изложенной выше, можно сделать следующий вывод: проблема развития познавательного интереса у учеников начальных по сей день является актуальной и продолжает рассматриваться и анализироваться достаточно подробно. Однако цель нашего исследования - определение уровня развития познавательного интереса у детей младшего школьного возраста, а также уровня заинтересованности учениками в проведении факультативных занятий в дополнение к урокам окружающего мира.

На основании данных проведенного исследования можно будет сделать вывод о значимости проведения дополнительных факультативных занятий для развития познавательного интереса у детей младшего школьного возраста.

Исследование проводилось на базе МОУ «Гимназия №1 г. Нерюнгри им. С.С. Каримовой», для проведения исследования мы посетили учащихся 3 А класса.

Для составления комплексной диагностики в ходе проведения исследования нами были использованы следующие методики: «Методика с конвертами» Г.И. Щукиной [4, с. 6], методика оценки уровня сформированности компонентов учебной деятельности Г.В. Репкиной и Е.В. Заики [5, с. 2].

На первом этапе работы нами была проведена диагностика по «Методике с конвертами» Г.И. Щукиной, где уровень развития познавательного интереса младших школьников определялся по качеству ответа на вопросы из конверта, выбранного ребенком следующим образом:

Высокий уровень - ответ на вопрос, требующий определенных знаний по теме (в том числе дополнительных), наиболее полно раскрывающий осведомленность ребенка в этой теме.

Средний уровень - ответ на вопрос, не требующий от ребенка особенно глубоких или дополнительных знаний, но раскрывающий тему вопроса в достаточном объеме.

Низкий уровень - ответ на вопрос, требующий от ре- бенка только поверхностных знаний по теме.

При обработке данных подсчитывалось количество детей, отвечавших на вопросы определенного уровня. В Таблице 1 представлены результаты диагностики учащихся младшей школы по уровням развития познавательного интереса, которые были распределены в соответствии со шкалой.

Согласно результатам, отраженным в Таблице 1, количество учащихся, чей уровень развития познавательного интереса определен как высокий равно 12. Это говорит о том, что большинство учащихся 3 А класса сосредоточены на более детальном и глубоком изучении тем, которые их интересуют, и стремятся к получению дополнительных знаний по этим темам. Однако если рассматривать каждую группу отдельно, то можно увидеть, что 7 учеников показывают средний и 3 - низкий уровень развития познавательного интереса. Данные показатели демонстрируют нам нежелание детей углубляться в изучаемые ими темы, отсутствие также желания задавать дополнительные вопросы, отсутствие, возможно, мотивации к более детальному изучению тем.

Следующим этапом нашего исследования была оценка сформированности компонентов учебной деятельности Г.В. Репкиной и Е.В. Заики с целью выяснить уровень их познавательного интереса на уроках.

Данное тестирование проводилось не с учащимися класса, а с их классным руководителем. Ему были предложены две анкеты - основная, состоящая из 37 вопросов, и дополнительная, состоящая из 34 вопросов. На основании вопросов из данной анкеты учителю было необходимо дать оценку деятельности каждого ребенка на уроке окружающего мира.

Результаты исследования приведены в Таблице 2

По результатам проведенного исследования, из общего количества учеников (22) 10 демонстрируют устойчивый познавательный интерес во время работы на уроке окружающего мира. 4 проявляют только ситуативный познавательный интерес в некоторых моментах урока. 2 ученика проявляют любопытство к уроку и изучаемой теме. 5 детей демонстрируют реакцию на новизну, реагируя на определенные изменения в структуре ведения урока или необычные задания, 1 ученик вообще не проявляет интереса к уроку.

Такие результаты свидетельствуют также о том, что достаточно большим количеством детей материал урока окружающего мира не усваивается в полном объеме из-за сниженного познавательного интереса именно на уроке окружающего мира. Поэтому нами также был проведен опрос «Хотел бы ты получать знания об окру- 
Таблица 1.

Результаты оценки познавательной активности младших школьников

\begin{tabular}{|l|c|c|c|c|c|}
\hline \multirow{2}{*}{ Школа } & \multirow{2}{*}{ Класс } & Количество учени- & \multicolumn{3}{|c|}{ Количество учеников, показавших } \\
\cline { 4 - 6 } & & ков классе & Высокий уровень & Средний уровень & Низкий уровень \\
\hline М0у «Гимназия №1» & $3 \mathrm{~A}$ & 22 & 12 & 7 & 3 \\
\hline
\end{tabular}

Таблица 2.

Сформированность познавательного интереса у учащихся ЗА класса

\begin{tabular}{|c|c|c|c|c|c|}
\hline \multicolumn{1}{|c|}{ Интерес } & Отсутствие интереса & Реакция на новизну & Любопытство & Ситуативный интерес & Устойчивый интерес \\
\hline Кол-во учащихся & 1 & 5 & 2 & 4 & 10 \\
\hline
\end{tabular}

Хотел бы ты получать знания об окружающем мире дополнительно, вне уроков?

Таблица 3.

\begin{tabular}{|c|c|c|c|}
\hline Отношение & Очень хотел бы & $\begin{array}{c}\text { Можно попробовать, но не знаю, } \\
\text { хочется ли мне }\end{array}$ & $\begin{array}{c}\text { Совсем не хочется тратить на это } \\
\text { свободное время }\end{array}$ \\
\hline Кол-во выборов & 15 & 4 & 3 \\
\hline
\end{tabular}

жающем мире дополнительно, вне уроков?». Результаты опроса представлены в таблице ниже.

Таким образом, большинство детей из общей выборки - 15 положительно относятся посещению дополнительных, факультативных занятий по окружающему миру. 4 человека не выражают особой заинтересованности в посещении факультатива, а 3 не изъявляют желания тратить свое свободное время на дополнительные занятия по этому предмету.

После проведенного исследования нами был сделан вывод, что познавательный интерес является не только важным в процессе обучения качеством личности, но и возможностью ребенка узнавать окружающий его мир вне зависимости от школьной программы. «Всеми возможными способами нужно воспламенять в детях горячее стремление к знанию и к учению» [2, с. 38]. Умение организовать занятие таким образом, чтобы у каждого ученика проявлялся устойчивый познавательный интерес, является необходимостью для учителя начальных классов, если он хочет добиться максимально полного усвоения программы наибольшим количеством учеников. Также важно уметь организовать дополнительные факультативные занятия по предмету, дабы повысить уровень развития познавательного интереса у детей, у которых данное качество находится на низком уровне развития.

В заключение можно сказать, что значимость дополнительных факультативных занятий в развитии познавательного интереса у детей младшего школьного возраста довольно высока. Дополнительные занятия, не стесненные формальными рамками урока, позволяют ребенку расслабиться, не думать о своих оценках и успеваемости, что способствует ускоренному восприятию информации. Познавательный интерес - это «естественный двигатель детского поведения», он является «верным выражением инстинктивного стремления; указанием на то, что деятельность ребенка сходится с его органическими потребностями». Вследствие чего, оптимальным решением учителя будет построение «всей воспитательной системы на конкретно учтенных детских интересах...» [1, с. 115]. Проведение дополнительных, факультативных занятий вне программы курса «Окружающий мир» способствует появлению у детей интереса к самому предмету, а также формированию устойчивого познавательного интереса не только к темам, которые рассматриваются непосредственно на уроке, но и к остальному миру, который их окружает и с которым они ежедневно контактируют.

Статья выполнена под руководством научного руководителя: к.п.н., доцента Мамедовой Л.В.

\section{ЛИТЕРАТУРА}

1. Выготский Л. С. Педагогическая психология.- М.: Педагогика-Пресс, 1999. - 536 с.

2. Коменский Я.А. Дидактические принципы (отрывки из «Великой дидактики»): Со вступительной статьей проф. А.А. КРАСНОВСКОГО. -- М: Государственное учебно-педагогическое издательство НАРКОМПРОСА РСФСР, 1940. - 93 с.

3. Рубинштейн С.Л. 0 мышлении и путях его исследования. — М.: Просвещение, 1988. - 412 с.

4. Сечина Г.П. Опытно-экспериментальное исследование игровых технологий как средства формирования познавательных интересов младших школьни- 
ков. $-2019 .-18 \mathrm{C}$.

5. Тюликова Г.А. Методика оценки уровня сформированности учебной деятельности (Г.В. Репкина, Е.В.Заика). - 2018. - 15 с.

6. Федеральный государственный образовательный стандарт

7. начального общего образования (утв. приказом Министерства образования и науки РФ от 6 октября 2009 г. N 373). - М. : Просвещение, $2010 .-29$ с.

8. Федеральный закон от 29.12.2012 N 273-Ф3 (ред. от 26.07.2019) «06 образовании в Российской Федерации» [Электронный ресурc] URL: http://www. consultant.ru/document/cons_doc_LAW_140174/ (дата обращения: 03.10.19).

9. Щукина Г.И. Формирование познавательных интересов у школьников. - М.: «Просвещение» 1984. - 176 с.

\section{( Б Богомолова Елена Алексеевна (helen_fletcher@mail.ru), Мамедова Лариса Викторовна (larisamamedova@yandex.ru).}

Журнал «Современная наука: актуальные проблемы теории и практики»

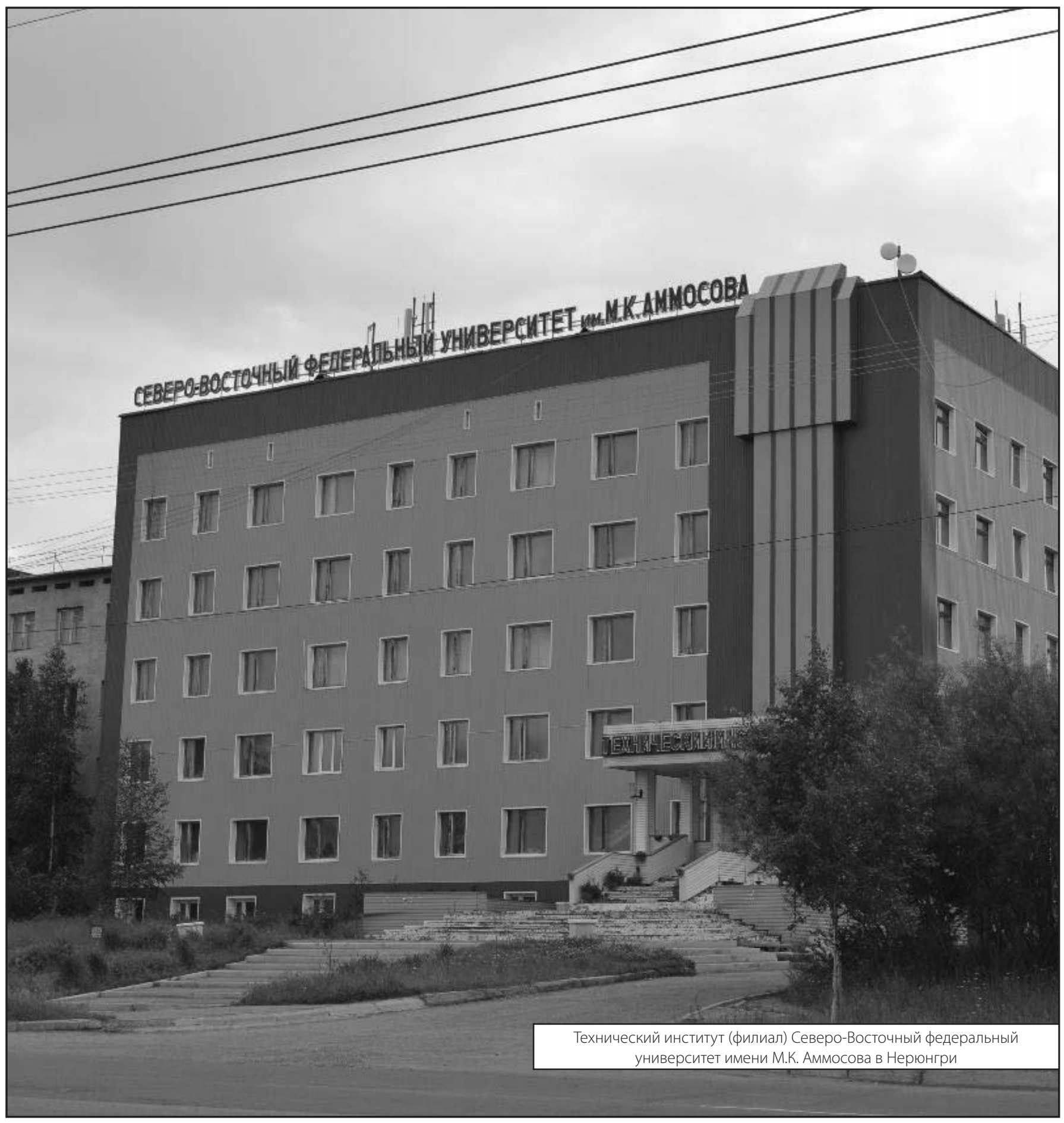

